THURSDAY, MAY 20, 1920 .

\author{
Editorial and Publishing Offices: \\ MACMILLAN \& CO., LTD., \\ ST. MARTIN'S STREET, LONDON, W.C. 2.
}

\author{
Advertisements and business letters should be \\ addressed to the Publishers. \\ Editorial communications to the Editor.
}

Telegraphic Address: PHUSIS, LONDON.

Telephone Number: GERRARD 8830.

\section{The Officers Training Corps and the Universities.}

$I^{N}$ $\mathrm{N}$ a leading article on "The Universities and the Army," in Nature for April 8, we referred to the Memorandum on the Army Estimates for I920-2 I published by the War Office, and quoted the words: "One of the important lessons of the war has been the extent to which the Army is dependent on the Universities." Of these lessons one especially was emphasised, viz. the necessity for the reorganisation of the Army on its educational side. We were told again and again, both during and after hostilities, that the war was primarily a scientific war-laboratory against laboratory, machine shop against machine shop, trained intelligence against trained intelligence-and it is gratifying to know that the War Office recognises that "the Universities responded to the call for help in a splendid manner." That they did so is an indisputable fact. Thousands of undergraduates and hundreds of their teachers, from junior assistant to full-fledged professor, switched off from classics, history, philosophy, natural science, and what not, to gunnery, engineering, motor transport, and so on. Chemical laboratories substituted investigations on explosives, anti-gas protectives, and smoke screens for routine qualitative and quantitative analysis; engineering laboratories concentrated their energies on the invention of depth charges, shell-gauges, and submarine engines; and the geologist relinquished the study of stratigraphy and palæontology to discover new sources of sand from which to manufacture glass. All this work was novel to the Universities, and, as many would add, foreign to their purpose and traditions; yet should another war of similar magnitude ever arise, can it be doubted that the Universities will again be called upon to play an even greater part in it than they did in the Great War of 1914-18?

NO. 2638 , VOL. IO5]
If this be so, and if the Army be regarded as a profession, should its officers not receive a professional training, and where more appropriately and effectively than in the Universities? One of the most enlightened features of Army reorganisation introduced by Lord Haldane in 1907 was the institution of the Officers Training Corps in connection with the Universities. Had this tentative scheme of professional training for future Army officers received proper encouragement and been developed on suitable and elastic lines, the War Office might have had at its disposal in the autumn of I9I4 a large reserve of trained officers who had passed through a properly devised University curriculum.

The military education committees of the various British universities and university colleges were recently sounded as to their views on the future of the Officers Training Corps, and from the replies received it would appear that most of them are unwilling to commit themselves to any plan of action until the attitude of the Army Council in reference to the Corps has been ascertained. What that attitude may be we have at present no means of finding out. We are informed that one of the largest Universities in the Kingdom answered the inquiry in the following terms: "The Military Education Committee are not of the opinion that it is desirable to take any further action at the present time until the Army Council have made a definite statement with regard to the future position of the Officers Training Corps, or to take any steps in regard to the creation of a Department of Military Studies until this official statement is issued." Several other Universities replied in similarly non-committal terms, and out of twelve, only one expressed any enthusiasm on the subject.

If the Army Council sincerely desires to make use of the Universities in the trairing of officers, let it say so in clear and unmistakable language, and indicate at the same time how and to what extent it is prepared to aid the Universities in carrying out its ideas. Some progress might be made, for example, if the Army Council would appoint a committee representing all departments concerned with Officers Training Corps, with power to act and not merely to hear and repori, to meet and confer with representatives of the Universities, who on their side could submit the special needs of the Universities regarding Officers Training Corps. We cannot get rid of the suspicion that the War Office authorities are unaware of the work and organisation of the 
newer Universities, and that they are still convinced that Great Britain has only two institutions worthy of the title. Have they any adequate conception, for example, of the extent and capacities for teaching and research of the faculties and departments of metallurgy, engineering, chemistry, and applied electricity at Sheffield, Leeds, Manchester, and Liverpool, to mention only one group of provincial Universities, and how it might be possible, in connection with a properly organised training corps, to provide instruction for cadets in those branches of specialised military work for which a particular University had special facilities and equipment, involving the application of science to war?

The Regulations governing the O.T.C. are dated I9r2, but we have learnt much since then, and it is essential before these Regulations are revised and re-issued that the Army Council should take the Universities into its confidence, and, in consultation with their representatives, produce a scheme of training that shall conform to University practice and be within the range of University capacity, while at the same time meeting the requirements of the Army Council in its effort to obtain suitably trained men to command the various units of the Army of the future.

\section{Relativity and Geometry.}

The Foundations of Einstein's Theory of Gravitation. By Erwin Freundlich. Authorised English translation by Henry L. Brose. Preface by Albert Einstein. Introduction by Prof. H. $H$. Turner. Pp. xvi+6r. (Cambridge: At the University Press, 1920.) Price 5 . net.

P URELY mathematical workers have often found occasion to remark on the prophetic vision of Riemann. He possessed that special genius which catches glimpses of truth, of no special significance to a contemporary, which one day are found to have an importance greater even than the seer himself had dreamed. Certainly this has proved so with much of Riemann's work. His famous Habilitationsschrift, "On the Hypotheses which lie at the Bases of Geometry,' was presented to the faculty of philosophy at Göttingen in $18_{54}$, and, in an English translation by Clifford, was brought to the notice of the British public in the columns of Nature (vol. viii., Nos. $183-84$, pp. $14-17,36,37)$. It may be permissible to quote one or two prophetic phrases :

"It seems that the empirical notions on which the metrical determinations of space are founded, the notion of a solid body and of a ray of light, cease to be valid for the infinitely small. We are therefore quite at liberty to suppose that the metric relations of space in the infinitely small do not conform to the hypotheses of geometry; and we ought in fact to suppose it, if we can thereby obtain a simpler explanation of phenomena."

It is worthy of note that Riemann never speaks of space itself as being non-Euclidean. $\mathrm{He}$ carefully refers always to the metric or measured relations. The "ground" of these metric relations is to be sought in the nature of the reality underlying space. Is that reality a discrete manifoldness, or is it continuous? If the latter, then the "ground of the metric relations" must be sought in the properties of that reality, or, as he says, "in binding forces which act upon it." Could anything be more prophetic of Einstein's conception of gravitation? Then, as if to anticipate the conservative and the scoffer of to-day, he continues :

"The answer to these questions can only be got by starting from the conception of phenomena which has hitherto been justified by experience, and which Newton assumed as a foundation, and by making in this conception the successive changes required by facts which it cannot explain. Researches starting from general notions, like the investigation we have just made, can only be useful in preventing this work from being hampered by too narrow views, and progress in knowledge of the interdependence of things from being checked by traditional prejudices."

With this open mind, and the work of Gauss, Lobatchevsky, and Bolyai on the geometry of figures on curved surfaces to provoke thought, Riemann faces the possibility that the geometry of three dimensions of actual material bodies may not be so simple as Euclid's system suggests. Geometry in the ordinary sense is, in fact, eliminated; the metrical relations of bodies are "studied in abstract notions of quantity" ; the results of calculation may afterwards be expressed in geometric form. Indeed, what is meant by the "length of a line," or a "line element," becomes far from clear from the geometrical point of view. It is merely some quantity which serves to distinguish one point from another. The question is asked: What type of magnitude may be constructed out of the quantities that serve to define two special points in a material body, which may conveniently be taken as a measure of their distinctness one from the other, first from a purely mathematical point of view, but afterwards by an empirical test of its abiding value. Riemann is led to use the general quadratic differential form as the simplest possible expression.

$$
\text { No. } 2638 \text {, vOL. IO5] }
$$

